\title{
Influence of Gravitational Noises on the Long-Range Order in Collagen
}

\author{
Kristina Zubow*1, Anatoly Zubow ${ }^{2}$ and Viktor Anatolievich Zubow ${ }^{1}$ \\ ${ }^{1}$ Zubow Consulting, Germany \\ ${ }^{2}$ Group of the Telecommunication Networks Division, Germany
}

Received: 阱 August 04, 2018; Published: 跳 August 13, 2018

*Corresponding author: Kristina Zubow , Group of the Telecommunication Networks Division, TU, Berlin, Germany

\section{Abstract}

For collagen obtained from young fish air bubbles, using the gravitation mass spectroscopy method (GMS) the dynamics of the long-range order (LRO) change in the whole domain ensemble up to 3 billion Da was studied. LRO was represented by the masses of the simplest domains (loops, spirals), sub micelle and micelle structures, seed fibrillary crystals and giant aggregates ( $2 \ldots . .3$ billion Da). The process of the LRO varying occurred under the influence of the gravitational noise (GN) from the universe. The form of the mass distribution in LRO depended on the age of the fish.

\section{Introduction}

The ageing of collagen as well as of other molecular systems occurs not only at the level of chemical processes, but also at the little-known level of LRO. On the other side it is known that LRO in molecular systems is formed under the influence of gravitational noises of the universe which can be represented as the effect of

sound waves on disperse systems. Here these heterogeneous structures were forced to form new structures with minimal potential energies. It was of interest to trace the dynamics of such events in the collagen LRO. The purpose of this work was to analyze LRO in collagen and the causes of its ageing as well as.

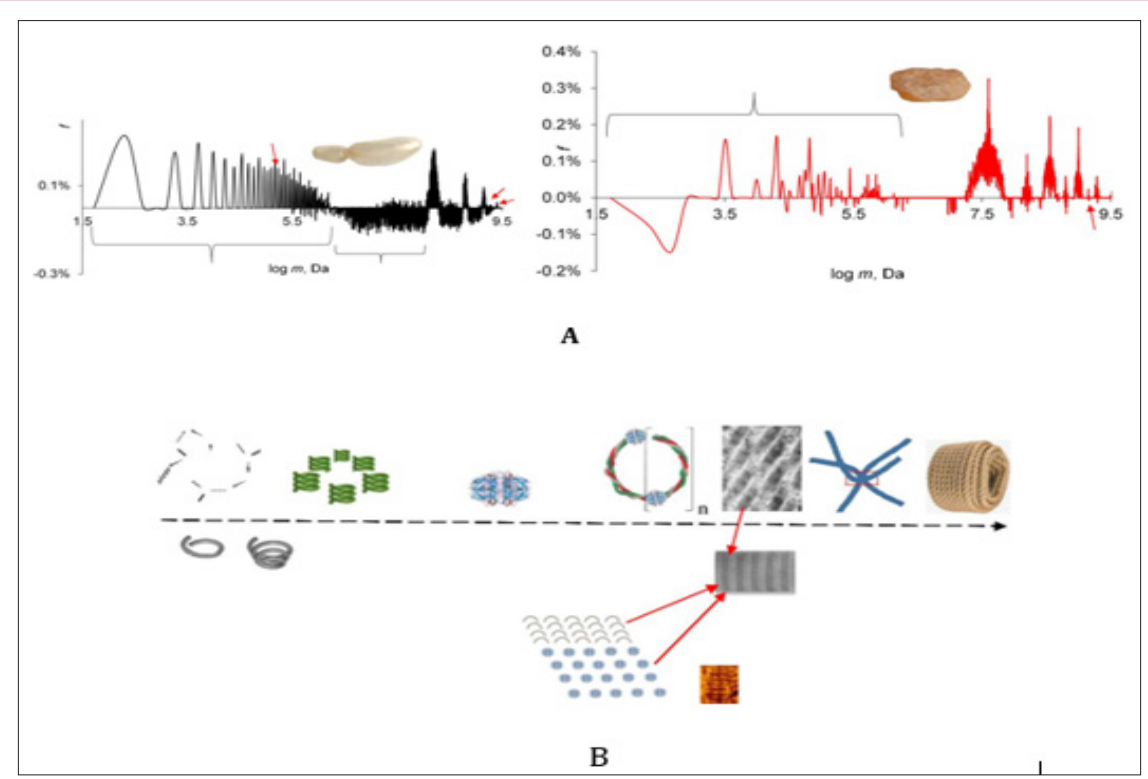

Figure 1: GMS spectra dry collagen from air bubble of young (A) and of two years old roach (B). The sub ensembles of mass concentrations (atom nuclei clusters) in collagen A were nominated as $1 S$... 4S, aged as S1 ... S8. For some signals, the labeling $1,3,11,20,127$ were given, this was the RASC number (repeating average structures in collagen) consisting of: Gly 22 -Pro \% $13 \%$ - Hyp $10 \%$ - Glu $9.8 \%$ - Ala $8 \%$ - Arg $7.6 \%$ (mass \%). 


\section{Material and Method}

Fresh and aged fish air bubble collagen (Figure 1) served as investigation objects. The GMS spectra were taken using the procedure described in [1] by means of weak shock waves. The spectra were then calculated with the help of the Zubow force constant $\mathrm{Z}=6.55 \mathrm{E}-15 \mathrm{~N} / \mathrm{m}$. Prior to the measurement the samples were dried at $320 \pm 5 \mathrm{~K}$. The positive signals in the spectra were ascribed to the energy part of the expanded domains in the whole mass ensemble (f), the negative (-f) - to that one of the collapsed domains. Remember once more that the GMS signals depend less on the concentration of the coils/domains, than on their mass (clusters of atom nuclei) dynamics (changes in conformations, configurations of individual chain fragments, movement of coils, and their forced deformation). Based on these properties the method made it possible to isolate the signals from the active mass clusters and to identify them.

\section{Results and Discussion}

The Figure showed the GMS spectra of collagen obtained from the air bubble of a young roach and of that one aged for 2 years. In the Table 1 the ensembles of mass clusters were briefly described. As visible the ageing processes of LRO affected all possible clusters of masses. However, while in the young collagen the relationship between collapsed and expanded clusters was nearly equally (52 to $48 \%$ ), in the aged ones the dominating collapsed, energyrich domains and micelles were sharply reduced (2\%). Here, in both ensembles of young and aged collagens the average mass of domains and micelles and their number of kinds were practically the same. The ageing process of domains in protein should be considered as a process of their forced adaptation to the effects of GN [1]. With prolonged exposure to GN, the "young" domains were fractionated into sub ensembles S2 ... S10. This process can be compared with the influence of sound on water. Here, GN stimulated the dominance of some domains and supramolecular structures and the energy subordination of other ones. Such differences in the construction of LRO should influence the macro characteristics of collagens and their ageing in various tissues of organisms. On the other hand, the obvious influence of GN on the protein LRO and the natural changes in the GN from the universe could be the reason for the different ways of the evolution. A similar phenomenon of ageing was discovered by us for liquids and synthetic polymers [1-7].

Table 1: Atom nuclei concentrations (domains) in collagens and their characteristics. The relation between the masses and the oscillation frequencies of domains was determined using the first Zubow equation [1]. $\mathrm{N}$ - number of domains in ensemble (number of signals), MGMS - average mass of all domains in ensemble (Daltons) and Dc - fraction of collapsed domains (-f values).

\begin{tabular}{|c|c|c|c|c|c|}
\hline Ensemble & Structures & MGMS, Da & Dc, $\%$ & $\mathbf{N}$ & $\mathrm{Hz}$ \\
\hline Whole, Figure $2 \mathrm{~A}$ & Domains, Micelles & $371,812,304$ & 52 & 2091 & $44,000 \ldots 5$ \\
\hline $1 S$ & Domains, spirals & 323,163 & 5 & 59 & $44,000 \ldots 247.8$ \\
\hline $2 \mathrm{~S}$ & Package of spirals & $39,287,386$ & 95 & 498 & $246 \ldots 31.8$ \\
\hline $3 S$ & $\begin{array}{l}\text { Agglomerates from } \\
\text { packages of spirals }\end{array}$ & $152,245,834$ & 9 & 284 & $31.8 \ldots 22.2$ \\
\hline $4 \mathrm{~S}$ & Sub micelles & $360,616,863$ & 95 & 418 & $22.19 \ldots 13.2$ \\
\hline $5 S$ & Micelles & $640,579,829$ & 1 & 104 & $13.21 \ldots 11.74$ \\
\hline $6 S$ & Super micelles & $980,302,441$ & 99 & 324 & $11.74 \ldots 8.73$ \\
\hline $7 S$ & Fibrillary seed crystals & $1,426,744,289$ & 3 & 118 & $8.72 \ldots 8.17$ \\
\hline $8 \mathrm{~S}$ & Fibrillary crystals & $1,704,671,064$ & 72 & 239 & $8.17 \ldots 6.56$ \\
\hline 9S & $\begin{array}{l}\text { Giant spirals and } \\
\text { hanks of spirals }\end{array}$ & $2,571,822,179$ & 2 & 47 & $6.56 \ldots 5.38$ \\
\hline Whole, Figure 2 B & Domains, Micelles & $363,753,879$ & 2 & 2072 & $44,000 \ldots 5$ \\
\hline $\mathrm{S} 1$ & Domains, spirals & 214,683 & 23 & 64 & $44,000 \ldots 247.8$ \\
\hline $\mathrm{S} 2$ & Package of spirals & 1.041 .826 & 100 & 14 & $103.5 \ldots 89.6$ \\
\hline S3 & $\begin{array}{l}\text { Agglomerates from } \\
\text { packages of spirals }\end{array}$ & $40,710,438$ & 0 & 585 & $76.17 \ldots 37.3$ \\
\hline S4 & Sub micelles & $88,105,128$ & 100 & 19 & $36.09 \ldots 32.76$ \\
\hline S5 & Micelles & $157,287,775$ & 19 & 86 & $28.23 \ldots 20.12$ \\
\hline S6 & Super micelles & $358,581,544$ & 1 & 589 & $20.12 \ldots 14.3$ \\
\hline S7 & Fibrillary seed crystals & $637,800,920$ & 26 & 34 & $12.98 \ldots 12.09$ \\
\hline S8 & Fibrillary crystals & $988,104,654$ & 0 & 510 & $10.65 \ldots 9.43$ \\
\hline S9 & $\begin{array}{l}\text { Giant spirals and } \\
\text { hanks of spirals }\end{array}$ & $1,433,447,622$ & 22 & 5 & $8.38 \ldots 8.27$ \\
\hline S10 & $\begin{array}{l}\text { Giant coils and hanks } \\
\text { of spirals }\end{array}$ & $1,920,590,692$ & 1 & 135 & $7.43 \ldots 7.01$ \\
\hline
\end{tabular}




\section{Conclusion}

Ageing of biological systems also occurs under the influence of gravitational noise of the universe. The dynamics of changes in LRO of proteins can affect the biochemical and evolutionary processes in the cell.

\section{References}

1. Zubow K, Zubow AV, Zubow VA (2014) The Way to the ETIs. Applied gravitational mass spectroscopy. Nova Sci. Publ. NY.

2. https://de.wikipedia.org/wiki/Datei:Fibers_of_Collagen_Type_I_-_TEM. jpg

3. Manuel E Than, Stefan Henrich, Robert Huber, Albert Ries, Karlheinz Mann, et al. (2002) The 1.9- $\alpha$ crystal structure of the noncollagenous
(NC1) domain of human placenta collagen IV shows stabilization via a novel type of covalent Met-Lys cross-link. Proc Natl Acad Sci USA 99(10): 6607-6612.

4. Stephanie Röper (2010) Strukturuntersuchungen an biologischen Materialien mitHilfe rasterkraftmikroskopiebasierender Nanotomographie. Dissertation. Chemnitz, den 23.

5. Zubow K, Zubow A, Zubow VA (2018) New Non-Invasive Determination of the Aortic Elasticity. Black Coffee vs. Milk. Horizons in World Cardiovascular Research. Ed. Eleanor H. Bennington. NY, Nova Publish. Inc 15: 157-180.

6. Wunderlich B (1973) Macromolecular Physics. Vol. I. Crystal Structure, Morphology, Defects. Academic Press, NY, London.

7. Matthew D Shoulders, Ronald T Raines (2009) Collagen Structure and Stability. Annual Review of Biochemistry 78: 929-958.
ISSN: 2574-1241

DOI: 10.26717/BJSTR.2018.07.001575

Kristina Zubow. Biomed J Sci \& Tech Res

(C) (P) This work is licensed under Creative Submission Link: https://biomedres.us/submit-manuscript.php
Commons Attribution 4.0 License

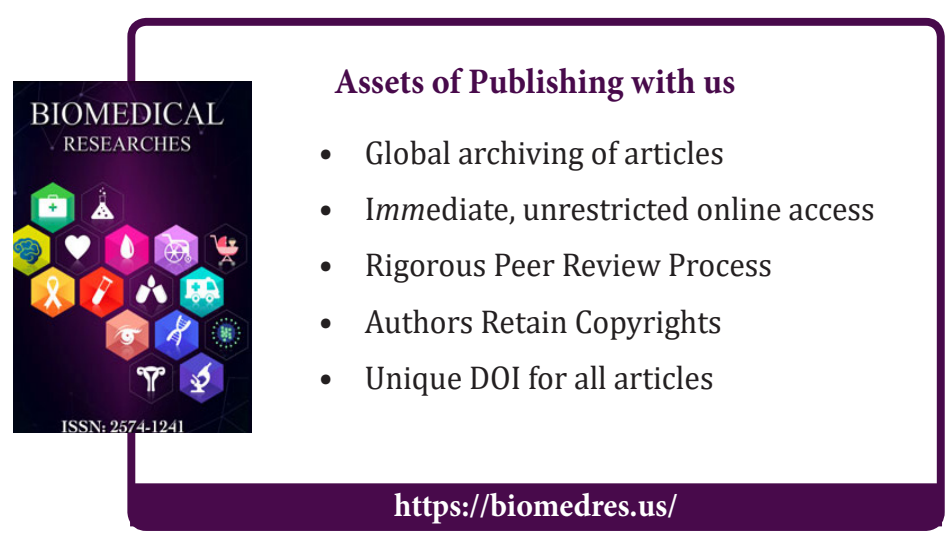

